\title{
Reflections on Mental Health Education of Left - behind Children in Rural Primary Schools
}

\author{
Yuan Chen \\ Major of Basic Psychology, School of Education and Science, Qufu Normal University (Qufu Campus), \\ Shandong, 273165, China
}

Keywords: Rural primary school; Left - behind children; mental health education

\begin{abstract}
Rural children left behind are a special group in the process of urbanization and rural resources integration. As the city's living costs and education costs are relatively high, school-age children have to be left behind to accept compulsory education in rural areas. Although some children are taken care of by the temporary guardian of the blood relationship, mental health education has become the focus of the whole society because of the separation of the parents, and mental health education has become a social topic of this times.

Mental health is a psychological state, which indicates the social individual is harmony with the environment and adapt to the social life .In childhood, mental health is the important content of love and intelligence education, including the maintenance of children's mental health status and the cultivation of high-level psychological quality. For the left-behind children, it is the organic combination between the conventional growth education and remedial education in the mental health education. The mental health has normal general intelligence, harmony interpersonal and adaptability.
\end{abstract}

\section{The current mental health status of rural children left behind}

With the influx of large numbers of rural labor into the city, rural children left behind became a significant increase in the number of groups. First of all, left-behind children and parents do not live together for a long time, the parents of the real conditions do not allow children to live with children and care for children. Second, most of the left-behind children live with their grandparents, and some of their children are taken care of by their grandparents while some children take care of themselves. Grandparents are more beloved for their children. Many left behind children in this favor gradually become self-centered, lack of tolerance of others. Thirdly, the educational environment in rural areas needs to be improved; school management and school education are relatively backward. Finally, the left-behind children are not subject to parental control, which caused a lot of bad habits gradually develop.

\section{The rural children left behind are introverted, rarely communicate with others}

Left-behind children do not get their parents to accompany; they should learn a variety of things in life and study to do their own. Once the problem is difficult, grandparents also have no ability to deal with. So the left-behind children had to bear too much pain and pressure. The mood for a long time been suppressed, the negative emotions are accumulated, so that they do not easily reveal their own inner situation to the teachers and students.

\section{Weariness is more common}

Parents of left-behind children work in big cities all year round, grandparents have lower level knowledge, some grandparents are illiterate, they are unable to counsel children to learn, left-behind children can only cope with their own difficulties. The compulsory education stage of the child usually has a poor concentration, low self-control characteristics, if they do not make their own strict requirements, indulge in online games, which will result in the decline of academic performance. In addition, the lack of confidence in the left-behind children, lack of concentration in 
the classroom result in weariness. Some parents think that reading is not useful, and the children affected by this are no longer concentrate on learning.

\section{The rural children left behind are sensitive, their emotions are volatile.}

Parents work in big cities for a long time, left - behind children lack of psychological communication; they will gradually show a psychological fragile situation. The small trivial things in life will violate the psychological line of left behind children, causing a greater impact on it, such as hatred, hostility and so on. Grandparents are more spoiled for their children; they will meet all the unreasonable demands of the child as much as possible. This creates a child self-centered, selfish consciousness. Many children in life once encountered a little frustration, which is not a matter of course, they will not be as brave as the normal children, and they will take temper, hatred and other extreme rebellious way to make misunderstanding, gradually expand this misunderstanding to violence.

\section{The development of bad habits}

Parents of left-behind children cannot be effectively supervised, and grandparents are frail and in poor health, they have no energy to care for the left behind children , and the left behind children have poor self-control ability and are unable to control the study time and play time. Some children are immersed in online games; some children are affected by bad social groups, such as smoking, abuse, theft or even robbery and other acts.

The status quo of mental health education of children left behind in rural primary schools in China

Parents go out to work for life, children stay at home to accept compulsory education, which are common reasons that the majority of left-behind children and parents separated. Since the lack of parental family and discipline of children, lack of spiritual conditions in rural areas, the psychological needs are in a neglected state for a long time.

\section{The educational philosophy is low}

Left-behind children in the rural state basically make grandpa grandmother as a temporary guardian; sub-generation support is easy to form school-age children's personality defects, such as capricious, spicy, and selfish. At the same time, the enrollment and education in the rural primary school are in the marginal state, the actual enrollment is limited, the teacher is equipped to meet the conventional teaching, psychological education is almost blank, the rural primary school has no professional mental health education teacher; basically do not set up mental health class.

\section{The educational content is backward.}

The cultural level of parents is limited, they generally concerned only with cultural knowledge learning, ignored the child's character training and mental health education. Moreover, due to long-term separation with their parents, children and parents make less emotional communication, children's psychological distress and trouble has no appropriate talk channels. The rural primary school has no psychological counseling qualification of professional teachers, due to the strength of teachers and teaching resources, mental health education has become an empty talk.

\section{The educational methods are improper.}

Because parents feel insecure for the children, they prefer to make up the main material to the child's emotional needs, ignoring the personality shaping, and the importance of mental health. In addition, the left-behind children in the school does not accept the mental health education curriculum, their emotional needs and psychological needs lack of effective positive response and health guidelines, which are easy to accumulate into psychological hidden, and ultimately affect the formation of personality. 


\section{The reasons for the mental health education of children left behind in rural primary schools}

The problems existing in the mental health education of left - behind children in rural primary schools reflect the defects of educational mechanism in three levels: family education, school education and social education. In recent years, the left-behind children are more and more, the mental health problems of left behind children gradually emerged, more and more people began to realize that the importance of left-behind children's mental health education, and began to look for reasons from the family, school and social.

\section{The effective guidance of parents is missing in family education}

Parents and children separate for a long time, which lead to the child's character growth, behavior, cognitive system in a state of exile. The social experience and experience of the parents have not had a positive impact on the child, and the source of knowledge of the part of the world's knowledge of the community is cut off and the child has a negative social impact. Children in childhood should feel care and security from the parents, which has no reason to deprive.

\section{The lack of active intervention mechanism in school education}

Due to the large loss of rural population, rural primary school is atrophy, rural primary school compulsory system is not optimistic. First of all, there is a serious shortage of funds for education, as shown in the table 2009 - 2011.The rural primary school accounted for about $90 \%$ of the total number of primary schools, and the corresponding investment in education funding is less than 65\%. In addition to school building, the teaching of software construction and teaching staff construction is basically stagnant or even in backward state. In some remote mountainous areas, primary school teachers still use substitute teachers, teachers' salaries and welfare benefits are not effectively guaranteed, and basic education facilities can not keep up with teaching needs. Therefore, the left behind children's mental health education class has no teacher and no effective mental health mechanism.

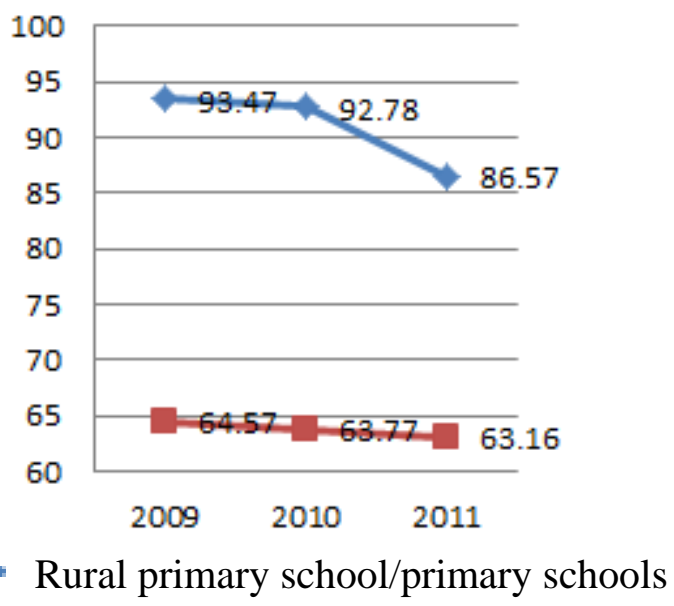

- Rural primary school/primary schools

- - Investment in education funding ofrural primary school/primary schools

Table. Number of rural primary schools and funding structure in 2009-2011 (unit:\%)

\section{The concern deviation in Social Education}

The local social forces have not paid enough attention to the left-behind children, and the administrative organizations with the villages and towns have focused on the economic construction, neglecting the growth and education of the school-age children, which lead to lack of care and attention from the administrative organizations. In addition, the social organization give the left-behind children's attention, effective care and upbringing support almost which rely to send gifts, that is love dedication, but the input of care and mental health care is the most needed of left behind children. 


\section{The main measures of improving the mental health education of rural children left behind}

\section{The family should enhance communication and the establishment of emotional ties}

Parents' guidance for children can help children form the right values. Parents decided to work in the city, they can bring the children together into the city, and this way can solve contradictions to let the parents take care of children. If parents cannot bring their children into the city, they need to take into account the daily care of children left behind. Parents stay as much as possible to accompany children to grow or work near which dilute the psychological distance with the child. Parents should keep talking with children, make video chat, and learn more about the lives of children left behind. Parents should actively communicate with the school teacher to understand the child's growth process problems.

\section{The school should strengthen education to promote mental health}

Schools should carry out boarding schools, requiring teachers to special supervision of boarding students, with strict rules and regulations and behavior to manage left-behind children. This way can help children stay in school to develop learning habits, to provide left-behind children to study counseling, supplement left-behind children the lack of family education and promote children's physical and mental health growth.

Schools use network channels to set up children's growth files. Growth records record the left-behind children's psychological changes, focusing on psychological fluctuations in the larger children, this way allow schools make better understand of the true situation of rural children left behind, which can be targeted to improve the mental health of children left behind.In addition, the school should also expand the teaching content; establish a care mechanism, through the various forms of bureaucratic activities to develop children's vision and mind, which will contribute to the formation of healthy mental state.

\section{The society should make more concern about improving the mental health education of left - behind children}

First of all, the social need to adjust the policy structure and make appropriate to the rural infrastructure construction and economic construction to control the rural left behind and empty nest status; Second, the community should form an effective care mechanism to improve the backwardness of basic education in rural areas, the community should establish a professional care organizations of the left behind children, make regular psychological counseling and care accompanied. Finally, the social should integrate high quality educational resources such as retired teachers, volunteer organizations, college students to send love and mental health education to the countryside, so that children can make healthy growth under the care of the community.

\section{Conclusion}

Children are the flowers of the motherland, whether in economically developed cities or in rural areas, every child should enjoy equal access to education and physical, and every child should enjoy equal mental health development rights. In the special period of economic development, most of the adults who worked as rural laborers made positive contributions to social development. At the same time, the mental health education of migrant children who were left behind in rural areas should be affected by society; we should make each left-behind child have the right to physical and mental health growth. 


\section{References}

[1]Conklin K A. Career and Educational Interests of Johnson County High School Students.[J]. Career Choice, 2000:75.

[2]Borg, Mary O'Malley|Plumlee, J. Patrick|Stranahan, Harriet A. Plenty of Children Left Behind: High-Stakes Testing and Graduation Rates in Duval County, Florida.[J]. Educational Policy, 2007, 21(5):695-716.

[3]Shen J T, Feng H E, Yang J Y. Mental health status and influencing factors of left-behind children in Peixian County rural areas[J]. Chinese Journal of School Doctor, 2016. 